\title{
DELINEATING SPATIAL MARKETS USING MULTIVARIATE TIME SERIES
}

\author{
Bruce L. Benson; Merle D. Faminow; Milton H. Marquis; \\ and Douglas G. Sauer*
}

\begin{abstract}
Recent advances in multivariate time series modeling techniques have produced statistical concepts and methods that may surpass many of the economic and antitrust market delineation procedures currently in use. The appropriateness of cointegration tests and vector error correction models for market delineation are developed in the context of a spatially linked oligopsony and then employed to determine whether a single economic market exists among spatially linked North American pork producers. Institutional detail and other time series information are also used to explore antitrust market issues.
\end{abstract}

\section{INTRODUCTION ${ }^{1}$}

Geographic market delineation should be an important first step in most empirical industrial organization studies, even though it is a step which often has been overlooked or assumed away (Stigler and Sherwin 1985). Similarly, market delineation is required in the analysis of market power for the application of laws such as the U.S. Clayton Act merger section, Sherman Act monopoly cases, and Canada's Competition Act. Thus, a large literature has developed on the subject of market delineation criteria and procedures. ${ }^{2}$ Indeed, a distinction between the "economic market" and the "antitrust market" has been drawn (Werden 1981; Spiller and Huang, 1986; Scheffman and Spiller 1987). Delineation of the economic market in which a firm operates involves determination of the geographic area encompassing all of the supply and demand forces that influence that firm's price (i.e., the area for which partial equilibrium analysis is valid), while an antitrust market presumably consists of a "group of producers and geographic area that could, if cartelized, profitably exercise market power" (Scheffman and Spiller 1987).

One market delineation procedure that has been proposed several times involves the application of time series econometric techniques to price data (Howell 1984; Klein et al. 1985; Uri and Rifkin 1985; Uri et al. 1985; Slade 1986; Higginson et al. 1988; Cartwright et al. 1989; Greenhut and Benson 1989; Benson and Faminow 1990). While this approach has been criticized for antitrust markets

\footnotetext{
*Distinguished Research Professor, Department of Economics, Florida State University; Professor of Agricultural Economics, University of Manitoba; Economist, Board of Governors of the Federal Reserve System; and Assistant Professor of Economics (deceased), Boise State University.
} 
(Werden and Froeb 1991), recent advances in multivariate time series modeling techniques, primarily as applied in the analysis of macroeconomic issues, have produced statistical concepts and methods that enhance or surpass many of the economic market delineation criteria and procedures currently in use and also offer new insights regarding antitrust market delineation.

When both buyers and sellers are spatially distributed and transportation costs are significant, perfect competition cannot arise (Greenhut 1971). Nonetheless, competition of a rivalrous or oligopolistic type is not precluded, as geographically separated firms can be linked together as a consequence of competition for service area boundaries. Prices are determined through a dynamic process of linked reactions and feedbacks in this case, and price relationships can be examined in order to obtain information about the geographic extent of any one firm's economic influence and the geographic area encompassing the supply and demand forces that influence that firm (Benson 1980; Greenhut and Benson 1989; Benson and Faminow 1990). This reactive price adjustment process can be represented by a class of statistical models called error correction mechanisms. Integrated processes that follow an error correction mechanism have been shown by Engle and Granger (1987) to be cointegrated. Thus, if a set of firms and/or exchanges are in the same spatially competitive economic market (and if their price series each contains a unit root, as most market-determined prices appear to) the series should be cointegrated. ${ }^{3}$ Cointegration-constrained vector error correction models can then be specified, and innovation accounting techniques can be used to measure both the speed and strength with which one set of prices responds to shocks arising with another set of prices. Cointegration and strong short-run dynamic effects, combined with detailed analysis of market institutions can provide powerful evidence that two or more firms and/or exchanges are in the same spatially competitive market.

The following presentation is divided into five sections beyond this introduction. Section II develops a general model of spatial competition and describes the resulting error correction mechanism representation. Implications are derived for measuring the extent of economic markets and for determining certain aspects of the dynamics of price adjustment that may have implications for antitrust markets. In order to demonstrate the use of these methods and the insights to be gained, a recent Canada Competition Law Case and the Canadian hog processing industry are described in Section III. Section IV then explores the question of whether there is a single North American economic market for hogs. Short-run dynamic aspects of market price determination are empirically examined in Section $\mathrm{V}$ in considering the potential definition of Alberta as an "antitrust market." Concluding comments appear in Section VI. 


\section{SPATIAL COMPETITION AND LOCALIZED COLLUSION}

Most F.O.B.-pricing spatial-competition models in the Hotelling (1929) tradition are static equilibrium models. Dynamic price adjustments in such a geographically linked oligopoly or oligopsony involve a series of reactions and feedbacks as the market adjusts to shocks. Every theoretical model implies a set of reaction functions (e.g., Löschian, Greenhut-Ohta, and Hotelling-Smithies or Cournot-Nash, and consistent conjectures equilibria) or strategies (e.g., minimax, tit-for-tat), but the time path of the reactions and feedbacks depends on characteristics specific to the industry in question (e.g., cost and demand functions, spatial frictions, information sets of rivals, stability in terms of entry and exit, and time horizon). ${ }^{4}$

The price adjustment process in the spatially competitive market can be expressed with a class of statistical models called error correction mechanisms. Each firm in the spatially competitive market is potentially subject to demand or cost shocks (some of which may be common to all firms). After a firm adjusts to an initial cost or demand shock, the other firms respond by adjusting their own prices. These adjustments follow each firm's particular reaction function or strategy. In addition, each firm changes its price based upon the spread that has opened between its price and the prices of competitors. To do otherwise would imply continuously giving up consumers in the face of incursions into a service area by a distant oligopolistic rival or inputs in the face of incursions into a supply area by a distant oligopsonistic rival.

The vector error correction model representing these pricing dynamics can be written

$$
\Delta \mathrm{Xt}=\gamma\left(\alpha^{\prime} \mathrm{X}_{\mathrm{t}-1}\right)+\mathrm{B}(\mathrm{L})\left(\Delta \mathrm{X}_{\mathrm{t}-\mathrm{i}}\right)+\epsilon \mathrm{t}
$$

where $\Delta X_{t}$ is the vector of price changes in period $t, \gamma$ is a matrix of response parameters to be estimated, $\alpha^{\prime}$ is an (n-k) $\mathrm{n}$ matrix whose rows correspond to a set of constraints reflecting the low frequency long-run relationships between the price series, $B(L)$ is an $n \times n$ matrix of polynomial lag operators, and $\epsilon_{t}$ is a vector of zero mean iid residuals with variance $\sigma^{2}$ and contemporaneous correlation matrix $\Omega$.

This model reflects a dynamic equilibrium relationship wherein the expression $\alpha^{\prime} \mathrm{X}_{\mathrm{t}-1}$ represents the extent to which the system is out of 'equilibrium,' or deviates from long-run relative price relations. The series are tied together over time by the long-run relationships in $\alpha^{\prime}$, ensuring that the series never move too far 'apart' from one another. Price adjustments in any period take into account both the size of the equilibrium error and the direction of that error. The equi- 
librium error need not be eliminated or even reduced in any particular period, but because $\alpha^{\prime} X_{t-1}$ is stationary, it will be mean reverting. The short-run, high-frequency components of the price adjustment process (the lag difference expressions in the above equation) allow the price series to move apart from one another in the short-run as shocks arise and each firm reacts to those shocks (as well as to the reactions of rivals). Thus, price changes in period $t$ reflect the extent to which prices in levels deviate from their long-run 'equilibrium' relationships, as well strategic price adjustments.

Integrated processes that follow an error correction mechanism have been shown by Engle and Granger (1987) to be cointegrated (the converse is also true; cointegrated systems can always be represented by an error correction mechanism). Thus, if the price series generated by a spatially competitive market each contains a unit root (most market-generated price series appear to contain unit roots), the series should be cointegrated.

Cointegration is a long-run concept, whereas antitrust market issues need not be. However, information about the presence of cointegration and the short-run dynamic analysis from the vector error correction models can be used to evaluate antitrust market issues as well. With the vector error correction model (VECM) constrained to adhere to the long-run cointegration relations, standard innovation accounting techniques typically used with Vector Auto Regression (VAR) models can be applied to evaluate the speed and strength with which each price series responds to reaction and feedback effects from the other series. ${ }^{5}$ In particular, the speed and strength with which a price series responds to shocks arising in other series can be evaluated both with variance decompositions and impulse response functions. Variance decompositions report the percent of the k-period ahead squared prediction error for a series that can be accounted for by orthogonal innovations in each of the series. Thus, for example, if 50 percent of the threeperiod ahead squared prediction error for price series A can be accounted for by innovations to price series $B$, then price series $B$ has a relatively large influence on the evolution of price series A. If after an appropriate number of periods of price adjustments and feedbacks working through a spatially linked interdependent economic market, a particular "candidate market for antitrust analysis" is relatively independent (i.e., if a relatively large portion of the forecast error variance of a particular price series can be explained by price shocks to that series' prices), then it might be appropriate to treat it as an antitrust market. Impulse response functions report the response of the system to initial period standard error shocks. Therefore, these functions can also be examined to see how long it takes for changes in a particular area's prices to generate responses elsewhere. Furthermore, if institutional changes occur, then changes in the degree of independence can be examined by analyzing data from different time periods. If 
an institutional change such as a tariff (Benson et al. 1994a) alters the degree of independence, that may suggest that the area is appropriate for antitrust consideration (e.g., another institutional change like a merger might produce greater independence). ${ }^{6}$ Similarly, significant changes in relative prices for different geographic locations after an institutional change may provide support for consideration of a particular area as an antitrust market. Thus, several important pieces of information can be obtained from analysis of a time series of pricing data, all of which can provide useful information that supports or contradicts the definition of a candidate market as an antitrust market.

The empirical example explored below focuses on a market for spatially dispersed inputs purchased by a relatively small number of spatially dispersed producers (a spatial oligopsony). Spatial competition for such inputs affects elasticities of input supply for only a small number of potential suppliers near a submarket boundary. Thus, firms at a particular location might profitably cooperate (or merge) to eliminate the localized or direct competition within a subsection of the economic market, lower price, and sacrifice some distant inputs, because the elasticity of supply for the bulk of their inputs is not affected by the indirect competition from distant locations. Thus, there are potential locational rents to be extracted through localized collusion (or merger) (Benson et al. 1990). Actions by the localized cartel (or merged firm) still lead to reactions and feedbacks among the distant competitors, and the cartel (or merged firm) may also react to distant actions that significantly affect the elasticity of supply for an important segment of its sub-market. Nonetheless, changes in the local price series could be primarily influenced by local occurrences under such circumstances, and only secondarily influenced by what happens elsewhere. This argument is a relative one, then, rather than an absolute one: the relative influences of price changes arising at distant locations could differ when one site involves a cartel (or a single firm formed through a merger) and another does not.

\section{THE CANADIAN HOG INDUSTRY AND THE CANADA PACKERS CASE}

Canadian hog production is dispersed among a relatively large number of small hog farmers all across Canada. Within Canada, Ontario produces over 30 percent of the country's hogs, Alberta about 14 percent, Manitoba about 12 percent, and Saskatchewan about 5 percent. Quebec's production has risen sharply over the last two decades, from about 17 to over 30 percent, while British Columbia and the Atlantic provinces produce only small shares. However, particularly during the period examined below, the prairie provinces tend to be net surplus 
producers while the eastern provinces tend to be net deficit producers, despite the relative concentration of demand in the East. Transportation costs for delivering hogs from hog producers to meat packers are significant, and meat packing is a weight-losing operation. Therefore, hogs are virtually always processed within the same province that produces them or in a contiguous province (or in certain parts of the U.S.), and the pork products are then shipped to consumer locations. As a result, the relatively small number of relatively large packers is dispersed all across Canada.

In March, 1980, the Alberta Pork Producer Marketing Board, along with individual plaintiffs, filed a $\$ 73$ million class-action suit against virtually all of the packing firms with plants in the province. ${ }^{7}$ It was alleged that between January 1965 and June 1977 the packing firms in Alberta had, through price fixing and market sharing, reduced competition and lowered prices for hogs in the province. Similar charges were made regarding the packers' outputs (pork cuts and port products). Partial settlement of the suit occurred in 1984 when three of the defendants (Gainers Foot, Ltd., Burns Meats, Ltd., and Swift Canadian, Ltd.) agreed to a settlement of $\$ 700,000$ plus court costs of $\$ 105,000$. In addition, the same three firms also pleaded guilty to charges of conspiring to lessen competition and were fined $\$ 125,000$ each. One firm, Intercontinental Packers, Ltd., pleaded guilty to charges regarding hog prices, but not regarding pork cuts. The other firm charged in the suite, Canada Packers Ltd., did not settle. The resulting case, Her Majesty the Queen Against Canada Packers, Ltd. and Intercontinental Packers, Ltd. (hereafter, the Canada Packers Case), went to trial, with a verdict rendered in January of 1988.

Price fixing is not per se illegal under Canadian law. Rather, the prosecution must demonstrate that there was a conspiracy to lessen competition "unduly" (Competition Act, Section 32 (1) (c)). A determination of whether a conspiracy might have unduly lessened competition requires delineation of the relevant market and consideration of other factors relating to the structure of the market in order to assess the behavior of the participants (The Queen v. J. W. Mills \& Sons Ltd., et al. (1986) 2 Ex. C. R. 275 at pages 308 and 309). Thus, a key issue in the Canada Packers Case was the definition of the market.

During the trial the prosecution generally described the market as the Province of Alberta, or on occasion, the Provinces of Alberta, Saskatchewan, and British Columbia. No formal effort to define an antitrust type market was made, but "market" share data, reflecting shares of hogs purchased in Alberta, were presented as evidence of the ability to lessen competition unduly. In particular, the five firms initially accused of conspiring accounted for 85 to 90 percent of the Alberta hogs purchased over the period. As further evidence of the relevance of the market definition, it was shown that Alberta packers purchased live hogs in 
Alberta and in the two neighboring provinces. ${ }^{8}$ The defense countered with evidence based on bivariate Granger causality tests (see Benson and Faminow 1990) that Alberta hog prices were linked with prices from other Canadian provinces as a result of spatial competition. The defense argument was based on the concept of the economic market rather than the antitrust market, and while Canadian courts do draw upon the United States' antitrust case law and related academic literature to a significant degree (in part because of the relatively small number of Canadian Competition Law cases), the prosecution failed to make the distinction between economic and antitrust markets. The Canada Packers case was decided in favor of the defendant by the Court of the Queens Bench of Alberta on January 15, 1988, in part because of the defense evidence that Alberta should not be defined as an economic market for hogs (indeed, the defense called only four witnesses, three of whom focused exclusively on the geographic market issue and the data used to demonstrate geographic price relationships). Thus, in addition to re-examining the issue of the geographic extent of the economic market for hogs by applying multivariate time series techniques developed since this case was tried (rather than bivariate tests), and by including a U.S. price series, the following analysis also considers the possibility that Alberta might be an antitrust market.

First, it is hypothesized that there is a single North American hog market. The hypothesis that all the market segments are linked together in the same economic market would be strongly supported if the price series is cointegrated with a single common trend and the price series exhibits significant short-run pricing dynamics. The concept of cointegration is closely linked to that of common trends (Stock and Watson 1988; Johansen 1988). The common trends in a system of equations might be thought of as the different dimensions in which the system might wander off (up to a maximum of $\mathrm{n}$ where $\mathrm{n}$ is equal to the number of series in the system). If a group of time series is cointegrated, the cointegrating vectors describe the constraints imposed on the system. The larger the number of constraints, the more stable the system and the fewer dimensions in which the system can wander off (the fewer the number of common trends) (Dickey et al. 1991). Finding a single common trend implies a fairly stable long-run relationship among the variables, and in this case, it would support a hypothesis of a single North American hog processing market. Finding two common trends implies a less stable, although still important, relationship among the price series. Finding the number of common trends to be equal to the number of series in the system implies no long-run equilibrium relationship. Such a system is not cointegrated.

The existence of a single economic market does not prove that localized collusion would be irrelevant, of course, but it does provide information for antitrust analysis in that it suggests that the potential monopsony power of packers located 
within any particular province is constrained by distant competition. If there is more than one common trend, however, then more than one economic market might be implied. For instance, the U.S. and the Canadian markets might be separate, or perhaps collusion in Alberta might have completely broken the spatial linkage.

As a second step, short-run dynamic analysis will be employed to further explore antitrust market issues. If after an appropriate number of periods of price adjustments and feedbacks working through the spatially linked interdependent oligopsony, a relatively large portion of the forecast error variance of the Alberta price series can be explained by price shocks to that series' prices, then Alberta is relatively independent and it might be appropriate to treat it as an antitrust market. Furthermore, if an examination of a second set of data from a period after the alleged period of collusion reveals that the degree of independence has fallen substantially, the implication that Alberta can be designated as an antitrust market is reinforced. Impulse response functions will also be used to evaluate the direction and timing of initial price responses to shocks in other price series and the duration of the adjustment process. Furthermore, simple comparisons of relative prices and the changes in relative prices can reveal the potential for anti-competitive effects. Thus, several different pieces of evidence will be drawn from the time series of prices from separate locations in order to explore the issue of antitrust market definition.

\section{THE ECONOMIC MARKET FOR HOGS}

Weekly average prices for dressed Index 100 hogs in the major Canadian exchanges of Toronto (Ontario), Winnipeg (Manitoba), Saskatoon (Saskatchewan), and Edmonton (Alberta), plus a composite series of live weight prices for hogs of comparable quality for eight U.S. markets is used here. ${ }^{9}$ Canadian prices were converted to U.S. equivalents using exchange rate data from the EHRA Macro Data Tape (Board of Governors of the Federal Reserve). The tape reports business day exchange rates, so average weekly exchange rates were constructed to form a series consistent with the price observations. ${ }^{10}$

Price series were obtained for two separate time periods. For the period from January 9, 1965 to December 28, 1968, 208 weekly observations were obtained. Alberta packers were alleged to be colluding during this period. The collusion allegedly continued through 1977 but the 1969-1972 period included the formation of marketing boards in Alberta, Manitoba, and Saskatchewan. This substantially altered the marketing institutions, so the 1972-1977 period involves the adjustments to a different institutional arrangement than the $1965-68$ period. ${ }^{11}$ Time 
series analysis of the entire period of alleged collusion would have to consider each of these time periods separately. In recognition of space constraints, and since the purpose here is simply to illustrate the potential implications of this approach, the 1969-72 and 1973-77 periods will not be presented ([the results are consistent with the implications drawn below, however (see Benson et al. 1994b)]. A second set of 417 observations (from January 9, 1978 through December 28,1985 ) represents a period when functional marketing boards were in place and after the period during which collusion was alleged to have occurred. This data will be examined in order to see if institutional change alters the degree of independence for Alberta.

Tests for the number of cointegrating relationships were fitted using Johansen's maximum likelihood methods (1988; Johansen and Juselius 1990). ${ }^{12}$ Results of these tests for the price series are reported in Table 1 . The number of common trends is determined by subtracting the number of cointegrating vectors ( $r$ in Table 1) from the dimension of the matrix ( 5 in this case). Thus, for the first period, the estimated test statistics using both the trace test and the maximal eigenvalue test, and a 95 percent confidence level, support a finding of three cointegrating relations and two common trends. Given $r \leq 3$ in the second period, and the earlier finding that all series are I(1), it follows that there are four cointegrating relations and one common trend in the second period. Clear long-run relation-

TABLE 1

Number of Cointegration Relations, Canadian and U.S. Price Series

\begin{tabular}{|c|c|c|c|c|c|}
\hline \multicolumn{3}{|c|}{ Trace Test } & \multicolumn{3}{|c|}{ Maximal Eigenvalue Test } \\
\hline Null Hypothesis 1 & $\begin{array}{l}\text { Critical } \\
\text { Value }\end{array}$ & $\begin{array}{c}\text { Test } \\
\text { Value }\end{array}$ & Null Hypothesis & $\begin{array}{l}\text { Critical } \\
\text { Value }\end{array}$ & $\begin{array}{l}\text { Test } \\
\text { Value }\end{array}$ \\
\hline \multicolumn{6}{|c|}{ First Period: January 9, 1965 - December 28, 1968} \\
\hline$r \leq 0$ & 70.0 & $106.2 *$ & $\mathrm{r}=0$ & 33.3 & $35.8 *$ \\
\hline $\mathrm{r}<1$ & 48.4 & $70.4 *$ & $r=1$ & 27.3 & $31.8 *$ \\
\hline $\mathrm{r}<2$ & 31.3 & $38.6 *$ & $\mathrm{r}=2$ & 21.3 & $22.6 *$ \\
\hline $\mathrm{r}<3$ & 17.8 & 16.1 & $r=3$ & 14.6 & 10.5 \\
\hline \multicolumn{6}{|c|}{ Second Period: January 9, 1978 - December 28, 1985} \\
\hline $\mathbf{r}<0$ & 70.0 & $158.9 *$ & $\mathrm{r}=0$ & 33.3 & $75.6 *$ \\
\hline$\overline{\mathrm{r}}<1$ & 48.4 & $83.3 *$ & $\mathrm{r}=1$ & 27.3 & $31.5 *$ \\
\hline $\mathrm{r}<2$ & 31.3 & $51.8 *$ & $r=2$ & 21.3 & $26.8 *$ \\
\hline $\bar{r}<3$ & 17.8 & $25.0 *$ & $r=3$ & 14.6 & $15.2 *$ \\
\hline
\end{tabular}

In this Table, $r$ denotes the number of cointegrating vectors. The dimension of the matrix (the number of equations - 5) less the number of cointegrating vectors gives the number of common trends.

* Reject $\mathrm{H}_{0}$ at the 95 percent confidence level. Critical values are from Table A2 of Johansen and Juselius (1990, p. 208). 
ships are therefore apparent in both periods, although the relationship is less stable in the first data period.

These test results provide support for the view that the North American market for slaughter hogs is a spatially linked oligopsony in each of the data periods analyzed. The finding of two common trends in the first period, however, suggests that, relative to the second period, prices were less tightly tied together. Canadian exports of both hogs and pork products to the United States increased substantially through the 1970 s and early 1980 s, so this finding may suggest that there were two economic markets for hogs in North America prior to this export growth, markets divided by the Canadian/U.S. border. Alternatively, perhaps Alberta was not tightly linked to other areas because of limits on spatial competition due to collusion, as alleged in the Canada Packers Case. In any event, the separate economic markets that appear to exist in the earliest data period apparently were subsequently linked together into a single economic market.

\section{SHORT-RUN DYNAMIC ANALYSIS FOR ANTITRUST MARKETS}

Most price changes in the North American hog market probably emanate from the U.S. and/or Eastern Canadian sub-markets, since demand for hogs is derived from pork demand and these areas are net pork importers. Thus, price innovations introduced into Ontario or U.S. prices (particularly during the second period) are most likely to reflect the historical adjustments that have occurred in the actual data. An ordering of the series beginning with the U.S. and then moving east to west across Canada was chosen a priori to reflect these primary sources of pork demand. This ordering is borne out by Higginson et al. (1988, p. 511), where VAR analysis of hog prices in the mid-to-late 1980s implied that U.S. prices led Ontario prices and that Ontario prices in turn led Western Canadian prices (an average of Alberta, Manitoba, and Saskatchewan prices). Furthermore, theoretically, the ordering of the Canadian provinces should maintain the linkage between contiguous geographic areas, so an east-to-west or west-to-east ordering was mandated. One concern with this approach, however, is the sensitivity of the analysis to the ordering of the system. The ordering of highly collinear series tends to inflate the percentages for the series considered first and deflate the percentages for the other series. The theoretical arguments regarding linked spatial oligopsony imply that these series should be highly collinear. Therefore, several different orderings were tested based upon relationships observed from the correlation matrix $\Omega$ for the five-variable system. The four Canadian price series were found to be highly collinear in each of the data periods and thus the ordering of the series has important ramifications for interpreting the relative strengths of relationships 
within each period, and the results described below must be considered with some caution. However, the conclusions that are based upon relative changes from period to period are not sensitive to the chosen ordering (indeed, this is one reason for considering such evidence).

Innovations to U.S. prices and Ontario prices are almost entirely accounted for by shocks to those prices and are largely unaffected by shocks in the other markets in each of the data periods. This result may reflect the fact that these areas are high pork demand regions, and that they are large enough so that internal dynamics dominate external effects (i.e., they might be reasonable candidates for antitrust markets, if antitrust violations by firms within them had been alleged, and in fact, the U.S. is likely to contain sub-markets that could be antitrust market candidates). Table 2 shows the decomposition of variance calculations for innovations to prices in the three western Canadian provinces of Manitoba, Saskatchewan, and Alberta respectively, the three major surplus-producing provinces for the first period (January 9, 1965 - December 28, 1968), and Table 3 shows the similar results for the second period (January 9, 1978 - December 28, 1985).

TABLE 2

Decomposition of Variance, First Period (1965-1968)

\begin{tabular}{|c|c|c|c|c|c|c|}
\hline Periods & $\begin{array}{c}\text { Standard } \\
\text { Error }\end{array}$ & U.S. & Ontario & Manitoba & Saskat. & Alberta \\
\hline \multicolumn{7}{|c|}{ Manitoba } \\
\hline 1 & 0.027 & 3.55 & 40.95 & 55.53 & 0.00 & 0.00 \\
\hline 2 & 0.029 & 10.15 & 38.85 & 50.66 & 0.23 & 0.11 \\
\hline 3 & 0.030 & 10.24 & 39.69 & 49.45 & 0.40 & 0.21 \\
\hline 4 & 0.030 & 10.75 & 39.56 & 49.02 & 0.42 & 0.25 \\
\hline 5 & 0.030 & 10.89 & 39.54 & 48.82 & 0.50 & 0.25 \\
\hline 6 & 0.030 & 10.97 & 39.51 & 48.75 & 0.52 & 0.25 \\
\hline \multicolumn{7}{|c|}{ Sakatchewan } \\
\hline 1 & 0.026 & 2.22 & 40.66 & 50.70 & 6.43 & 0.00 \\
\hline 2 & 0.030 & 12.44 & 36.58 & 40.31 & 10.64 & 0.03 \\
\hline 3 & 0.030 & 12.57 & 37.11 & 39.39 & 10.89 & 0.05 \\
\hline 4 & 0.030 & 12.91 & 37.16 & 39.13 & 10.75 & 0.05 \\
\hline 5 & 0.030 & 13.12 & 37.17 & 38.96 & 10.70 & 0.05 \\
\hline 6 & 0.031 & 13.17 & 37.15 & 38.92 & 10.71 & 0.05 \\
\hline \multicolumn{7}{|c|}{ Alberta } \\
\hline 1 & 0.022 & 3.68 & 34.18 & 22.32 & 2.27 & 37.56 \\
\hline 2 & 0.025 & 10.77 & 37.38 & 18.10 & 2.65 & 31.10 \\
\hline 3 & 0.026 & 11.45 & 39.11 & 17.17 & 2.54 & 29.71 \\
\hline 4 & 0.026 & 11.82 & 39.15 & 16.83 & 2.79 & 29.41 \\
\hline 5 & 0.026 & 12.06 & 39.13 & 16.67 & 2.76 & 29.38 \\
\hline 6 & 0.026 & 12.19 & 39.13 & 16.58 & 2.79 & 29.32 \\
\hline
\end{tabular}


TABLE 3

Decomposition of Variance, Second Period (1978-1985)

\begin{tabular}{|c|c|c|c|c|c|c|}
\hline Periods & $\begin{array}{c}\text { Standard } \\
\text { Error }\end{array}$ & U.S. & Ontario & Manitoba & Saskat. & Alberta \\
\hline \multicolumn{7}{|c|}{ Manitoba } \\
\hline 1 & 0.025 & 10.25 & 51.79 & 37.96 & 0.00 & 0.00 \\
\hline 2 & 0.029 & 15.39 & 53.65 & 29.42 & 1.10 & 0.45 \\
\hline 3 & 0.029 & 15.68 & 53.27 & 29.24 & 1.36 & 0.45 \\
\hline 4 & 0.029 & 15.78 & 52.56 & 29.54 & 1.39 & 0.73 \\
\hline 5 & 0.029 & 16.17 & 52.35 & 29.37 & 1.38 & 0.74 \\
\hline 6 & 0.029 & 16.08 & 52.08 & 29.69 & 1.41 & 0.74 \\
\hline \multicolumn{7}{|c|}{ Saskatchewan } \\
\hline 1 & 0.025 & 9.95 & 48.95 & 24.82 & 16.28 & 0.00 \\
\hline 2 & 0.028 & 14.08 & 52.88 & 19.62 & 13.41 & 0.00 \\
\hline 3 & 0.029 & 15.39 & 52.04 & 19.30 & 13.16 & 0.10 \\
\hline 4 & 0.029 & 15.46 & 51.59 & 19.41 & 13.17 & 0.37 \\
\hline 5 & 0.029 & 16.15 & 51.09 & 19.18 & 13.22 & 0.36 \\
\hline 6 & 0.029 & 16.09 & 50.90 & 19.44 & 13.21 & 0.36 \\
\hline \multicolumn{7}{|c|}{ Alberta } \\
\hline 1 & 0.024 & 7.71 & 37.80 & 16.30 & 16.91 & 21.56 \\
\hline 2 & 0.029 & 13.89 & 45.30 & 12.36 & 11.31 & 17.14 \\
\hline 3 & 0.030 & 15.18 & 43.90 & 11.84 & 11.19 & 17.89 \\
\hline 4 & 0.030 & 15.38 & 43.70 & 12.02 & 11.13 & 17.77 \\
\hline 5 & 0.030 & 15.70 & 43.48 & 12.06 & 11.08 & 17.68 \\
\hline 6 & 0.030 & 15.67 & 43.34 & 12.20 & 11.16 & 17.62 \\
\hline
\end{tabular}

Comparing dynamic implications from period to period, Tables 2 and 3 indicate that after six periods of price adjustments and feedbacks working through the spatially linked interdependent oligopsony, approximately 29.32 percent of the forecast error variance of the Alberta price can be explained by shocks to Alberta's own price in the earliest period, for instance, and about 17.62 percent in the second period. Ontario accounts for 39.13 percent and 43.34 percent in the two periods, while the United States accounts for 12.19 and 15.67 percent, Manitoba accounts for 16.58 and 12.20 percent, and Saskatchewan accounts for 2.79 and 11.16 percent. The actual magnitudes of these various percentages are sensitive to ordering, but relative magnitudes are robust. The primary difference in the variance decomposition results for Alberta between the two periods is that Alberta price innovations are explained in the latter period to a lesser extent by shocks to Alberta's own price and to a greater extent by shocks to the other price series (results that are not sensitive to ordering). The competitive link with Saskatchewan, Alberta's immediate neighbor to the east, appears to be much more important in the second period, for instance, and both outlets for surplus pork 
products (Ontario and the U.S.) are also somewhat more important. Note that because Alberta is last in the ordering, its own percentage is deflated relative to other orderings. However, the relative changes always appear.

These variance decomposition results can provide some insights regarding Alberta as a potential "antitrust" market. It is clear that Alberta is not as independent as Ontario (or the U.S.), but the most appropriate provinces to compare Alberta to are probably Manitoba and Saskatchewan, which, like Alberta, tend to be surplus pork production areas. In the first period, it appears that Alberta is relatively independent from the forces of spatial competition as compared to its immediate neighbor, Saskatchewan, but not compared to Manitoba. Perhaps both Alberta and Manitoba could qualify as antitrust markets then, given allegations of collusion (or a proposed merger). What percentage constitutes "sufficient" independence? Like so many other statistics that are used in antitrust analysis (e.g., market shares, Hirfindal Indexes, LIFO and LOFI tests for market area, crosselasticities, or residual demand elasticities), there is no clear-cut answer. Therefore, results such as these must be considered in the context of a body of evidence. For instance, by examining the changes in percentages after a series of institutional changes have occurred, we see that institutional change can affect both Alberta's and Manitoba's degree of independence, but these institutional changes do not affect Saskatchewan. Thus, it follows that an institutional change such as collusion or a merger could increase the relative independence of Alberta or Manitoba, but probably not Saskatchewan. Of course, Ontario, Manitoba, and the U.S. all have important impacts on the dynamics of Alberta pricing during the first period. Therefore, it is not clear that Alberta is sufficiently independent so that if a cartel was in place it could unduly lessen competition. Perhaps additional information will shed some light on the question.

If a localized cartel is effective, it may mean that adjustments to the forces of spatial competition take longer, implying once again that it may be appropriate to consider the sub-markets as independent in the short run. Impulse response functions for each series were estimated for a 12-period (three-month) time horizon. In addition, 90 percent confidence bands were constructed by estimating the mean and variance of the impulse response functions using Monte Carlo integration methods. These results allow evaluation of the direction and timing of precise responses to shocks in other price series and the duration of the adjustment process. Analysis of short-run pricing dynamics using impulse response functions for both periods indicates significant responses from all price series in the first few periods following a shock, and confirms results from variance decompositions that significant interactions occur between all price series in both periods. Two sample impulse response functions are displayed in the two panels of Figure 1, where the response in each period of the Alberta price series in log-differences 
FIGURE 1

Impulse Response Function and $90 \%$ Confidence Band:

Log Alberta to a Unit Shock in Log Ontario

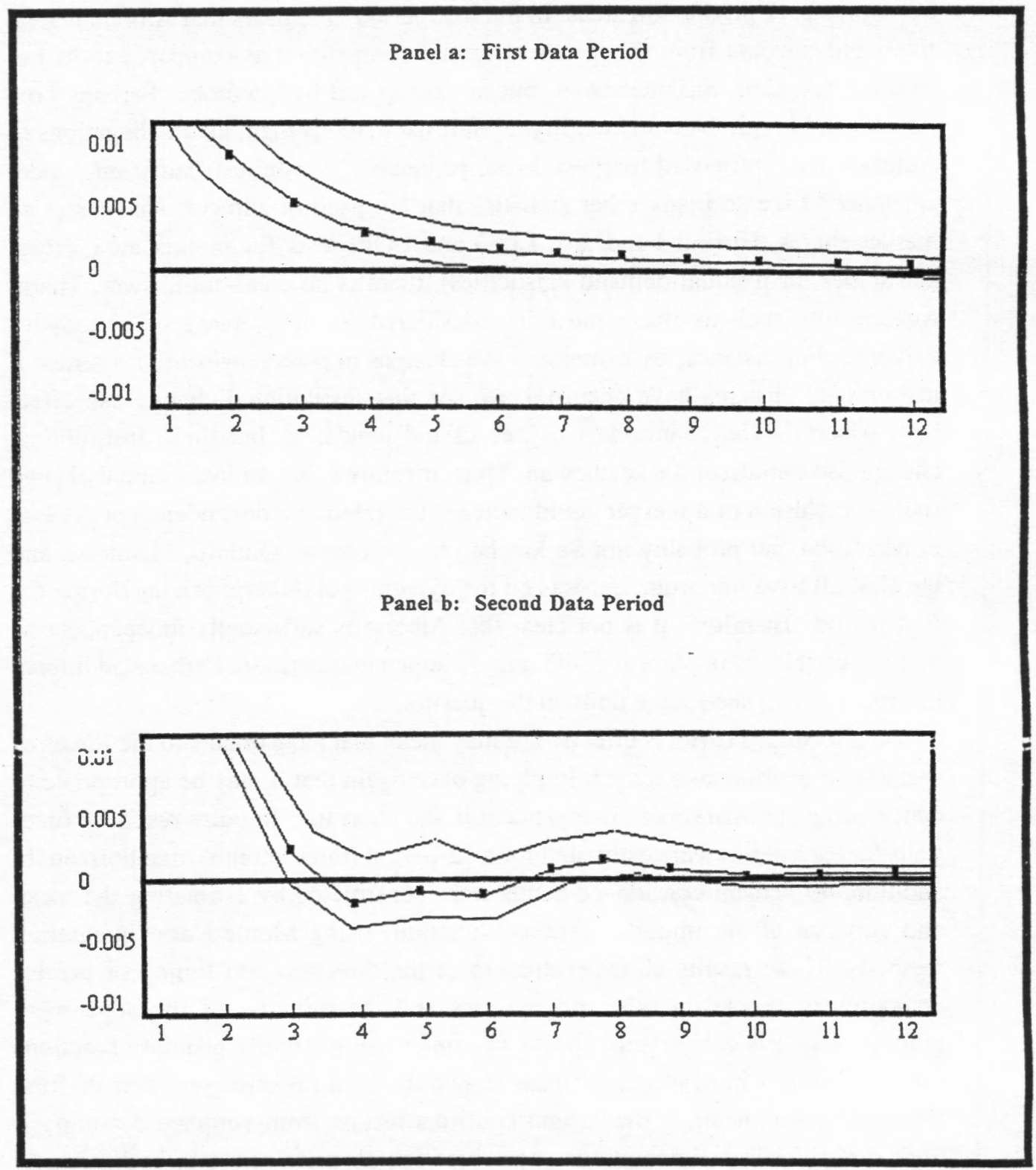


to a one standard deviation shock to the Ontario price series in log-differences are depicted. ${ }^{13}$ Similar functions were derived for all price series' responses to shocks in all other price series, but they are not presented due to space constraints. Therefore, the following discussion focuses on the Alberta results shown in Figure 1 relative to the other price series and the changes that appear to have occurred from the first to the second period.

Notice that Figure 1, Panel a indicates that it takes at least seven and perhaps eight weeks for the impact of a shock to Ontario's prices to fully play out its effects on Alberta prices. In contrast, the impacts of Ontario's price shock on Manitoba and Saskatchewan are not significantly different from zero after the third or fourth weeks. Again, Alberta appears to be relatively independent in that it resists incorporating the full impact of price changes for a longer period of time. Indeed, Alberta's responses to Ontario may be more like the U.S. responses than like other Canadian provinces' responses, because U.S. responses are also stretched out for about seven weeks. ${ }^{14}$

Alberta's response to a shock in the second data period (Figure 1, Panel b) looks virtually identical to the Manitoba and Saskatchewan responses. All three provinces have no significant responses after the second week, and all three look quite different from the U.S. impulse response function, where significant positive and negative oscillations in price may continue for up to six weeks. ${ }^{15}$ At any rate, it is once again clear that changes instituted between these two periods substantially altered the degree of independence for Alberta's hog prices. Alberta was different from the other provinces in the first data period, and similar in the second. If institutional changes can produce such changes in pricing dynamics, perhaps it is appropriate to consider Alberta as an antitrust market. An examination of relative prices corroborates this position.

Table 4 compares mean prices during the two data periods. These comparisons illustrate that Alberta hog prices were lower than other Canadian prices in the first period, and that they rose relative to the other provinces' prices between the first and the second period. All three of the western provinces' prices, however, rose relative to Ontario's prices. Thus, the rising prices in Alberta need not reflect the end of a collusive effort. After all, an equally plausible explanation of these relative price changes is that the formation of the marketing boards in Alberta, Saskatchewan and Manitoba created market power on the seller side of the sub-markets in these provinces, allowing the hog producers to raise prices to levels comparable to Ontario, where a marketing board had been in place for a much longer period. ${ }^{16}$ Of course, whether collusion is the reason for Alberta's relatively insulated position in the first period or not, it does appear that some degree of short-term insulation existed. Thus, once again, it may be appropriate to consider Alberta as an antitrust market. 
TABLE 4

t-tests for Differences in Means

Between the 1965-68 and 1978-85 Time Periods ${ }^{1}$

\begin{tabular}{|c|c|c|c|c|}
\hline Series & & $\frac{1 / 9 / 65-12 / 28 / 68}{\text { Mean }}$ & $\frac{1 / 9 / 78-12 / 28 / 85}{\text { Mean }}$ & $t$-test ${ }^{2}$ \\
\hline Alberta & (A) & $\$ 27.04$ & $\$ 55.84$ & 59.16 \\
\hline Saskatch. & (S) & 27.95 & 55.33 & 57.43 \\
\hline Manitoba & (M) & 28.83 & 55.36 & 56.89 \\
\hline Ontario & (O) & 30.51 & 57.23 & 57.86 \\
\hline U.S. & (U) & 21.91 & 50.68 & 65.40 \\
\hline$(A-U) / U$ & & 0.24 & 0.11 & -14.03 \\
\hline$(S-U) / U$ & & 0.28 & 0.10 & -19.95 \\
\hline$(M-U) / U$ & & 0.32 & 0.10 & -23.87 \\
\hline$(\mathrm{O}-\mathrm{U}) / \mathrm{U}$ & & 0.40 & 0.14 & -26.96 \\
\hline$(\mathrm{S}-\mathrm{A}) / \mathrm{A}$ & & 0.03 & -0.01 & -21.35 \\
\hline$(\mathrm{M}-\mathrm{A}) / \mathrm{A}$ & & 0.07 & -0.01 & -31.23 \\
\hline$(\mathrm{O}-\mathrm{A}) / \mathrm{A}$ & & 0.13 & 0.03 & -28.70 \\
\hline$(\mathrm{U}-\mathrm{A}) / \mathrm{A}$ & & -0.19 & -0.09 & 14.76 \\
\hline$(A-S) / S$ & & -0.03 & 0.01 & 21.77 \\
\hline$(\mathrm{M}-\mathrm{S}) / \mathrm{S}$ & & 0.03 & 0.00 & -32.01 \\
\hline$(0-S) / S$ & & 0.10 & 0.04 & -18.67 \\
\hline$(U-S) / S$ & & -0.21 & -0.08 & 20.38 \\
\hline$(\mathrm{A}-\mathrm{M}) / \mathrm{M}$ & & -0.06 & 0.01 & 31.94 \\
\hline$(\mathrm{S}-\mathrm{M}) / \mathrm{M}$ & & -0.03 & -0.00 & 31.85 \\
\hline$(\mathrm{O}-\mathrm{M}) / \mathrm{M}$ & & 0.06 & 0.03 & -9.27 \\
\hline$(\mathrm{U}-\mathrm{M}) / \mathrm{M}$ & & -0.24 & -0.08 & 24.01 \\
\hline$(\mathrm{A}-\mathrm{O}) / \mathrm{O}$ & & -0.12 & -0.02 & 29.18 \\
\hline$(\mathrm{S}-\mathrm{O}) / \mathrm{O}$ & & -0.09 & -0.03 & 18.97 \\
\hline$(\mathrm{M}-\mathrm{O}) / \mathrm{O}$ & & -0.06 & -0.03 & 9.28 \\
\hline$(\mathrm{U}-0) / 0$ & & -0.28 & -0.11 & 26.55 \\
\hline
\end{tabular}

All prices in U.S. dollars.

2 All are significantly different at the .05 percent level of confidence. The $t$-statistic is computed by dividing the difference between the means by the square root of the sum of the variances divided by their respective number of observations.

\section{CONCLUSIONS}

The theoretical models which underlie the expectation that a number of geographically separate firms or exchanges are part of the same economic market imply that prices are simultaneously determined in a dynamic process of reactions 
and feedbacks among all of the separate exchanges (Benson 1980; Benson and Faminow 1990; Greenhut and Benson 1989). Thus, bivariate tests for Granger causality may suffer from misspecification biases, and multivariate time series tests for cointegration and for the number of common trends in the various price series appear to be more appropriate theoretically, as they test hypotheses relating to the extent of an economic market.

In this study, multivariate time series procedures are employed with a sample of prices from Canadian and U.S. hog exchanges to test the hypothesis that there is a single North American hog market. The test results indicate that during the 1965-68 period the North American hog market may have been split along the U.S./Canadian border, or possibly Alberta was not tightly linked to the other areas. These separate economic markets were linked together into a single economic market during the $1978-85$ period.

An examination of the dynamic relationships between sub-markets can also offer insights regarding the potential that one of the sub-markets might be defined as an antitrust market. In this regard, Alberta packers were accused of price setting during the earlier period of time analyzed here. The results from the dynamic price analysis, coupled with an analysis of relative prices for a period of time when collusion was alleged to have occurred as well as a period of time after a Competition Act suit was filed, indicate that Alberta might have been appropriately defined as an antitrust market even though it could not be considered as an economic market. The procedures and results presented here offer useful insights regarding the potential for defining an antitrust market in a price-fixing case under Canadian Competition law, where price fixing is not, per se, illegal. They may be less useful in a merger case, however. In essence, since the concept of an antitrust market for merger analysis requires looking into the future at the effects of a hypothetical change in sub-market structure, inferences drawn from data generated under a past and therefore different market structure have to be considered with caution. Indeed, in the case of mergers (and, of course, the antitrust market concept comes from the Department of Justice Merger Guidelines), Stigler and Sherwin (1985) assert that the antitrust market concept is non-operational, although many others disagree (e.g., Scheffman and Spiller 1987). Nonetheless, useful insights can be gleaned from this approach, which can either support or contradict other information in the effort to define a particular antitrust market. Furthermore, the economic market is a much less hypothetical concept and the approach suggested here for testing to see if firms or exchanges are in the same economic market is superior to the techniques which have been used in the literature up to this point. 


\section{ENDNOTES}

1. An earlier version of this paper was presented at an AES invited Session at the American Economic Association meetings, New Orleans, January 1992. We wish to thank the session organizer/chairman, Pat Welch, and all of the panelists for their insightful comments. We are also grateful to Paul Beaumont, Stefan Norrbin, and an anonymous referee for their helpful discussion of the techniques employed.

2. See Benson and Faminow (1990) or Greenhut and Benson (1989) for reviews of the geographic market delineation literature, and Baker and Bresnahan (1985) for delineation of antitrust markets.

3. Note, however, that the converse need not be true. A finding of cointegration may not be sufficient to conclude that the firms and/or exchanges are in the same spatially competitive market.

4. The price adjustment process, however, can be described in a heuristic fashion similar to the non-spatial arguments described by Bresnahan (1981). See Benson et al. (1994b).

5. This two-step procedure of identifying cointegration relationships and then evaluating the dynamic price adjustment process with vector error correction models provides a means for overcoming several criticisms of the use of price data in market delineation (see, for example, Werden and Froeb 1991). First, comparison of price data in levels often leads to spurious correlation because of the effects of common influences. The common response has been to use first differences, which eliminate most of the effects of common influences, but also eliminates all information about potential long-run relationships between the levels of the variables (Hendry, 1986). Cointegration constraints and vector error correction models provide a means for reintroducing the long-run relationships among the levels of the variables, without reintroducing the nonstationarities of the undifferenced data. Second, even when using differenced data, common shocks may still lead to correlation between variables that otherwise are not economically related. Common practice when testing for cointegration is to first identify deterministic elements (e.g., time trends or seasonal effects) and either filter them from the data or account for them in the cointegration test critical values. Innovation accounting analysis will also reveal very limited pricing dynamics among these series. Third, using measures of the speed and strength with which a price series responds to shocks arising in other series will be sensitive to the frequency of the data employed (Werden and Froeb, 1991). Nonetheless, economic theory and common sense should indicate whether responses can be meaningfully considered rapid or slow, and thus this criticism is of little practical importance. Werden and Froeb (1991) also criticize Horowitz' (1981) absolute 
speed of adjustment criteria because autocorrelation in the data may lead to incorrect conclusions. However, the vector error correction models, as well as the tests for cointegration, include lagged values of all variables, and if properly specified, autocorrelation in the data will have been accounted for in the estimation process.

6. As with other price correlation techniques, this analysis uses historical data, so an implication that an area was not very independent in the past may not extrapolate into the future. After all, if the issue of concern is the potential future impact of a proposed merger, then the resulting structural change could alter the pricing dynamics from what is detected using a time series of past prices [see Benson et al. (1994a; 1994b) for examples of how institutional changes can substantially change pricing dynamics]. However, the approach may be very useful if the issue is one of past monopolization or collusion. Furthermore, if some institutional change can be observed that has substantially altered the degree of independence in the past, that may suggest that another institutional change (e.g., a merger) could have similar results.

7. Canadian law allows provincial governments to establish marketing. boards for agricultural commodities. Hog producers in most of the provinces now market their hogs through their respective marketing boards. See Benson et al. (1994b) for details.

8. A shipment approach a la Elzinga and Hogarty (1973) is implicit in the prosecution's market area arguments, although hog carcasses were purchased for processing by Alberta packers from more distant areas, and hogs from Alberta were shipped to other areas, including the U.S.

9. A sufficiently complete weekly price data series is not available for Quebec, in part because of the different marketing procedures in that province. However, analysis of shorter periods when Quebec data were available implies that Quebec and Ontario prices are highly collinear.

10. The Canadian and U.S. price series are still not precisely comparable, due in part to the difference in selling procedures in the two countries. The Canadian grading system ties the actual payment for a hog directly to the quality of the hog. This contrasts to the U.S., where hogs are primarily sold on a liveweight basis. Nonetheless, changes in pricing dynamics and relative prices can be explored.

11. The first hog marketing board was established in Ontario in 1946, but the other provinces did not follow suit for several years. On October 31, 1969, a board began selling all hogs marketed in Alberta through a teletype auction system, and Manitoba and Saskatchewan established boards to act as sales agents in 1971 and 1972, respectively. Thus, this period of institutional transition is dropped from the analysis. Of course, the fact that these institutional changes correspond to part of the period when collusion was alleged means that the changes 
that our analysis detects between our two time periods cannot be attributed exclusively to the break-up of an alleged cartel [Benson et al. (1994b)]. In 1985, a countervailing duty was placed on Canadian hogs exported to the United States, with dramatic impacts on pricing dynamics [Benson et al. (1994a)], so the postcollusion data period ends prior to this event. Note that the data consists of weekly average prices, so lagged and feedback effects that occur in less than a week will be masked. Subsets of this data (1965-1980) were used in Benson and Faminow (1990), Faminow and Benson (1990), and Benson, Faminow, and Fik (1992), but they used simple bivariate Granger causality tests with data from the Canadian exchanges, and only Benson and Faminow (1990) were concerned with geographic market delineation, focusing on the economic market concept. In addition, Benson et al. (1994b) explore some of the consequences of marketing board formation and changes in marketing board institutional arrangements using the techniques and the data employed here.

12. Unit root tests were performed using the augmented Dickey-Fuller procedure. These tests indicate that each of the five price series for each of the two periods contains a single unit root and they are each integrated of order 1 . Thus, tests for cointegration can be applied to these data. Additional tests for the presence of deterministic trends indicate only weak support for the presence of a time trend in the first period and no evidence of a trend in the second period. Various lag length tests were performed for each of the time periods [see Benson et al. (1994b), note 5 for discussion of such tests]. For the first period, only two lags were required to produce a reasonable model specification, while four lags were required for the second data period.

13. See Lütkepohl and Reimers (1992) for a discussion of impulse response functions in error correction models, and an explanation for why they are particularly useful in the interpretation of cointegration results.

14. On the other hand, while Ontario clearly incorporates a shock to the U.S. price faster than the other provinces do, there does not appear to be a substantial difference in response timing between the U.S. and Manitoba, Saskatchewan, and Alberta, suggesting that while Alberta may be relatively independent from Eastern Canada, that may not be the case with regard to the United States.

15. The Canadian provinces' responses to a U.S. price shock in the second data period are all quite similar as well, although Saskatchewan and Alberta appear to have three weeks of significant responses, while Ontario and Manitoba have two.

16. Alternatively, it could suggest that the boards made the market more efficient by establishing more efficient marketing mechanisms. A reduction in transactions costs could allow the price of hogs to rise without increasing the total cost to packers. This alternative is not born out by the experience of Alberta pack- 
ers, however, where all of the private large hog packers have exited. The Alberta board purchased one of the largest packers in the province, and the provincial government owns a second.

\section{REFERENCES}

Baker, J. B., and T. F. Bresnahan. "The Gains from Merger or Collusion in Product-Differentiated Industries." Journal of Industrial Economics 332 (1985): 427-444.

Benson, B. L. "Spatial Competition: Implications for Market Area Delineation in Antimerger Cases." Antitrust Bulletin 25 (1980): 729-749.

Benson, B. L., and M. D. Faminow. "Geographic Price Interdependence and the Extant of Economic Markets." Economic Geography 66 (1990): 47-66.

Benson, B. L., M. D. Faminow, and T. J. Fik. "Conduct in Spatial Markets: An Empirical Analysis of Some General Implications of Spatial Pricing Behavior." Papers in Regional Science 71 (1992): 15-30.

Benson, B. L., M. D. Faminow, M. H. Marquis, and D. G. Sauer. "Intra-National Effects of a Countervailing Duty on the U.S./Canadian Hog Market." Review of Agricultural Economics 16 (1994): 187-201.a.

Benson, B. L., M. D. Faminow, M. H. Marquis, and D. G. Sauer. "The Impact of Provincial Marketing Boards on Price Relations and Pricing Dynamics in the North American Slaughter Hog Market." Applied Economics 26 (1994): 677-688.b.

Benson, B. L., M. L. Greenhut, and G. Norman. "On the Basing Point System." American Economic Review 80 (1990): 584-588.

Bresnahan, T. F. "Duopoly Models with Consistent Conjectures." American Economic Review 71 (1981): 934-945.

Cartwright, P. A., D. Kamerschen, and M. Huang. "Price Correlation and Granger Causality for Market Definition." Review of Industrial Organization 4 (1989): 79-98.

Dickey, D. A., D. W. Jensen, and D. L. Thornton. "A Primer on Cointegration with an Application to Money and Income." Federal Reserve Bank of St. Louis Review 73 (1991): 58-78.

Elzinga, K. G. and T. F. Hogarty. "The Problem of Geographic Market Delineation in Antimerger Cases." Antitrust Bulletin 18 (1973): 45-81.

Engle, R. F. and C. W. G. Granger. "Cointegration and Error Correction: Representation, Estimation and Testing." Econometrica 55 (1987): 251-276.

Faminow, M. D. and B. L. Benson. "Integration of Spatial Markets." American Journal of Agricultural Economics 70 (1990): 49-62. 
Froeb, L. M., and G. J. Werden. "Residual Demand Estimation for Market Delineation: Complications and Limitations." Review of Industrial Organization 6 (1991): 33-48.

Greenhut, M. L. A Theory of the Firm in Economic Space. Austin, TX: Lone Star Publishers, 1971.

Greenhut, M. L. and B. L. Benson. American Antitrust Laws in Theory and in Practice. Aldershot, England: Avebury, 1989.

Hendry, D. F. "Economic Modelling with Cointegrated Variables: An Overview." Oxford Bulletin of Economics and Statistics. 48. Reprinted in Long-Run Economic Relationships. R. F. Engle and C. W. J. Granger, (eds.). Oxford: Oxford University Press, 1986, 51-63.

Higginson, N., M. Hawkins, and W. Adamowicz. "Pricing Relationships in Interdependent North American Hog Markets: The Impact of the Countervailing Duty." Canadian Journal of Agricultural Economics 36 (1988): 501-518.

Horowitz, I. "Market Definition in Antitrust Analysis: A Regression-Based Approach." Southern Economic Journal 48 (1981): 1-16.

Hotelling, H. "Stability in Competition." Economic Journal 39 (1929): 41-57.

Howell, J. "A Comment on Horowitz's Market Definition in Antitrust Analysis, A Regression Based Approach." Journal of Reprints for Antitrust Law and Economics 14 (1984): 1163-1170.

Johansen, S. "Statistical Analysis of Cointegration Vectors." Journal of Economics and Dynamic Control 12 (1988): 231-25.

Johansen, S., and K. Juselius. "Maximum Likelihood Estimation and Inference on Cointegration"With Applications to the Demand for Money." Oxford Bulletin of Economics and Statistics 52 (1990): 169-210.

Klein, C., E. J. Rifkin, and N. D. Uri. "A Note on Defining Geographic Markets." Regional Science and Urban Economics 15 (1985): 109-119.

Lütkepohl, H., and H. E. Reimers. "Impulse Response Analysis of Cointegrated Systems." Journal of Economic Dynamics and Control 16 (1992): 53-78.

Scheffman, D. T., and P. T. Spiller. "Geographic Market Delineation Under the U.S. Department of Justice Merger Guidelines." Journal of Law and Economics 30 (1987): 123-148.

Slade, M. E. "Exogeneity Tests of Market Boundaries Applied to Petroleum Products." Journal of Industrial Economics 34 (1986): 291-303.

Spiller, P. T. and C. J. Huang. "On the Extent of the Market: Wholesale Gasoline in the Northeastern United States." Journal of Industrial Economics 35 (1986): 131-145.

Stigler, G. J. and R. A. Sherwin. "The Extent of the Market." Journal of Law and Economics 28 (1985): 555-585. 
Stock, J. H., and M. W. Watson. "Testing for Common Trends." Journal of the American Statistical Association 83 (1988): 1097-1107.

Uri, N. D., and E. J. Rifkin. "Geographic Markets, Causality and Railroad Deregulation." Review of Economics and Statistics 67 (1985): 422-428.

Uri, N. D., J. Howell, and E. J. Rifkin. "On Defining Geographic Markets." Applied Economics 17 (1985): 959-977.

Werden, G. J. "The Use and Misuse of Shipments Data in Defining Geographic Markets." Antitrust Bulletin 26 (1981): 719-737.

Werden, G. J. and L. M. Froeb. "Correlation, Causality, and All That Jazz: The Inherent Shortcomings of Price Tests for Antitrust Market Delineation." Economic Analysis Group Discussion Paper 91-6, 1991. 